\title{
Effect of Welding on Microstructure and Mechanical Properties of an Industrial Low Carbon Steel
}

\author{
Zakaria Boumerzoug $^{1}$, Chemseddine Derfouf ${ }^{1}$, Thierry Baudin ${ }^{2}$ \\ ${ }^{1}$ Department of Mechanical Engineering, Biskra University, Biskra, Algeria \\ ${ }^{2}$ Université Paris-Sud 11, ICMMO, Laboratoire de Physico-Chimie de l'Etat Solide, Orsay, France \\ E-mail: zboumerzoug@yahoo.fr,derf_dany@yahoo.fr,Thierry.Baudin@u-psud.fr \\ Received February 5, 2010; revised April 12, 2010; accepted April 18, 2010
}

\begin{abstract}
In this work, the effect of arc welding on microstructures and mechanical properties of industrial low carbon steel $(0.19$ wt. \% C) was studied. This steel is used for making gas storage cylinders. In order to realize the objective, optical microscopy, EBSD, X-ray diffraction, and hardness tests were used. Different zones and some phases are identified. New microstructural phenomenons are observed by using EBSD technique.
\end{abstract}

Keywords: Steel, Welding, HAZ, Ferrite

\section{Introduction}

Welding is a process of joining materials into one piece. Generally, welding is the preferred joining method and most common steels are weldable. The phase transformation and mechanical behavior after the welding of many steels have been investigated. For example, Bayraktar et al. [1] have studied the grain growth mechanism during the welding of interstitial free steels. Observations in the welded joints indicate the presence of very large grains near the fusion line and these are oriented along the directions of the heat flow. Concerning the welding of low carbon steels, it has been shown that the graincoarsened zone (GCZ) and heat affected zone (HAZ) are very critical since embitterment is concentrated in these areas [2].

It is also known that the final microstructures and mechanical properties of welded steel depend on some parameters like percentage of carbon and presence of others elements such as sulfur or phosphorus. Low carbon steels that have less than $0.25 \%$ carbon, display good welding ability, because they can be generally welded without special precautions using most of the available processes. Concerning the previous studies related to the welding of low carbon steel, there are limited publications [2-8]. For example, Gural et al. [2] have studied the heat treatment in two phase regions and its effects on microstructure and mechanical strength after welding of the low carbon steel. On the other hand, Eroglu and Aksoy [3] investigated the effect of initial grain size on microstructure and toughness of intercritical heat-affected zone of low carbon steel.

Concerning the present study, it has been chosen to investigate the effect of welding on industrial low carbon steel used for making of gas storage cylinders. Optical microscopy, EBSD, X-ray diffraction, and hardness tests have been used as characterization tools.

\section{Experimental Procedure}

The chemical composition of the base metal is given in Table 1.

Steel electrodes were used to deposit the welds using the shielded metal arc welding process. The chemical composition of the weld metal is presented in Table 2.

Figure 1 illustrates a part of welded sheets of a gas cylinder and the sample size used in this study. The surface studied $\mathrm{S}$ is indicated in this figure.

For metallographic observation, the specimens were etched with $2 \%$ nital for $20 \mathrm{~s}$ and consequently the microstructures of the base, weld and the heat affected zone were defined. Specimens were prepared for Electron Back Scattered Diffraction (EBSD) analysis using standard sample preparation method. A Zeiss 940SEM with a tungsten filament was used. The SEM device is coupled with automatic $\mathrm{OIM}^{\mathrm{TM}}$ (Orientation Imaging Microscopy) software from the TSL Company. The hardness across the weld was measured by microhardness tester using a 2 $\mathrm{kg}$ load. In addition, X-Ray Diffraction (XRD) was used to determine the main phases in welded steel by using $\mathrm{CuK} \alpha$ radiation. 
Table 1. Chemical composition of the base metal (0.19 wt. \% C).

\begin{tabular}{ccccccccc}
\hline $\mathrm{C} \%$ & $\mathrm{Si} \%$ & $\mathrm{Mn} \%$ & $\mathrm{P} \%$ & $\mathrm{~S} \%$ & $\mathrm{Al} \%$ & $\mathrm{Mn} \%$ & $\mathrm{Nb} \%$ & $\mathrm{Ti} \%$ \\
\hline 0.19 & 0.25 & 0.4 & 0.025 & 0.015 & 0.09 & 0.009 & 0.05 & 0.03 \\
\hline
\end{tabular}

Table 2. Chemical composition of electrode, wt \%.

\begin{tabular}{ccccccccc}
\hline $\mathrm{C} \%$ & $\mathrm{Si} \%$ & $\mathrm{Mn} \%$ & $\mathrm{P} \%$ & $\mathrm{~S} \%$ & $\mathrm{Al} \%$ & $\mathrm{Nn} \%$ & $\mathrm{Nb} \%$ & $\mathrm{Ti} \%$ \\
\hline $0.06-0.12$ & 0.01 & $0.40-0.6$ & 0.025 & 0.025 & - & - & - & - \\
\hline
\end{tabular}

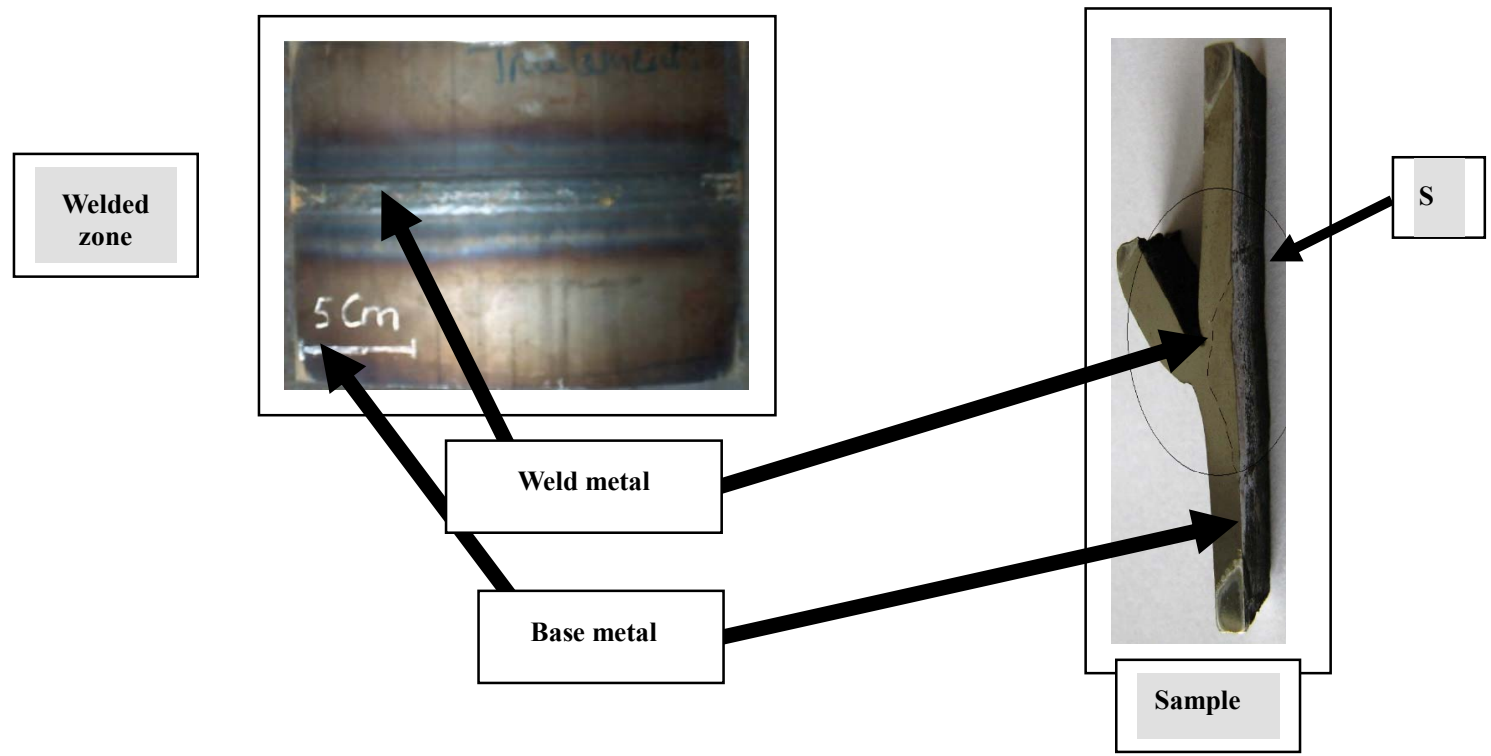

Figure 1. Part of welded sheets and sample used in the study. (S: Surface studied).

\section{Results and Discussion}

In the first part of this paper, the microstructure of base metal of industrial low carbon steel $(0.19$ wt. \% C) is presented. In the second part, the effect of welding on the microstructure evolution is illustrated.

\subsection{Base Metal}

Typical microstructure of sheet (base metal) is composed of ferrite and small regions of pearlite $\left(\alpha-\mathrm{Fe}+\mathrm{Fe}_{3} \mathrm{C}\right)$ at grain boundaries edges and corners (Figure 2(a)). Figure 2(b) shows an EBSD image of the base metal, which is largely composed of equiaxed ferrite grains.

Figure 2(c) illustrates a histogram of grain size which indicates that average grain size is $10 \mu \mathrm{m}$. On the other hand, Figure 2(d) shows curve of misorientation distribution (blue) which is near the istropic materials (red).

For low magnification (Figure 3), the bands of perlite-rich area (banding) were observed. This macrosegregation phenomenon, which is called banding, is due to the presence of high percentage of $\mathrm{Mn}(0.4-0.5 \%)$ in these zones. In more alloyed weld metals, elements such as chromuim and molybdenum can be found to be segregated in these areas [9].

\subsection{After Welding}

In order to clarify the effect of welding on sheets, the microstructures of welded joints were analyzed using optical microscopy and EBSD. The EBSD map of nearest region to HAZ (Figure 4) shows the effect of direction heat flow on elongation of ferrite grains. Bayraktar et al. [1], have observed in interstitial free steels that the welded joints are characterized by the presence of very large grains near the fusion line and these grains are oriented along the directions of the large heat flow.

This strongly "oriented" structure is in some aspects very similar to certain solidification microstructure, whose morphology depends also on heat flow. On the other hand, it has been found that solidification theory can be applied to welding $[10,11]$.

Concerning the heat-affected zone (HAZ), Figure 5 illustrates clearly the microstructures of this zone. It contains 


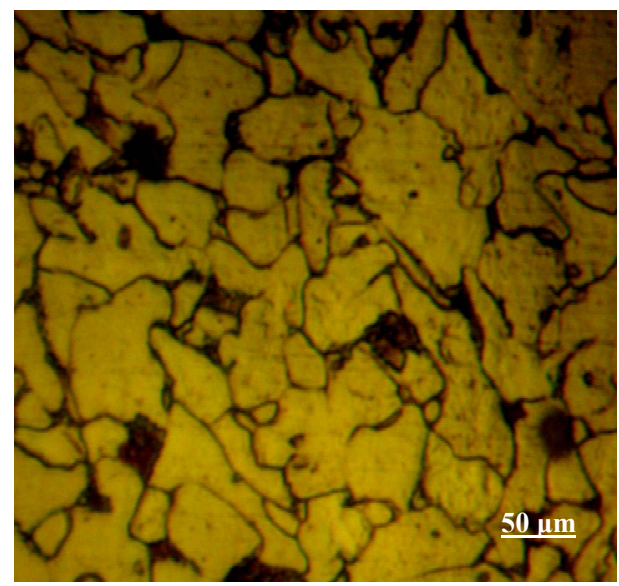

(a)

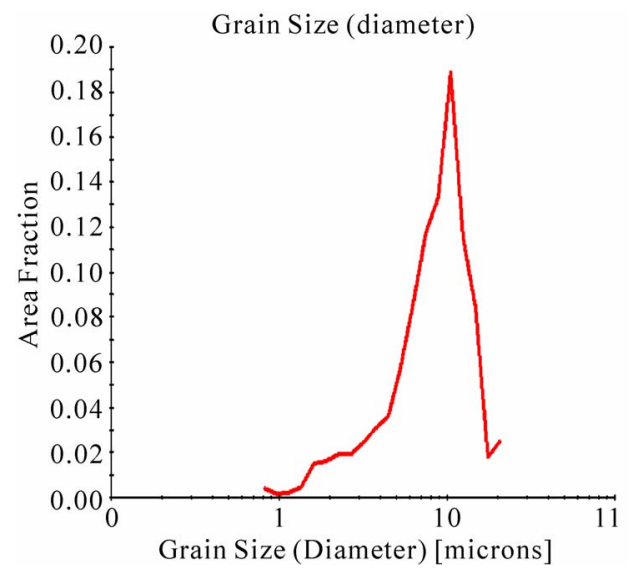

(c)
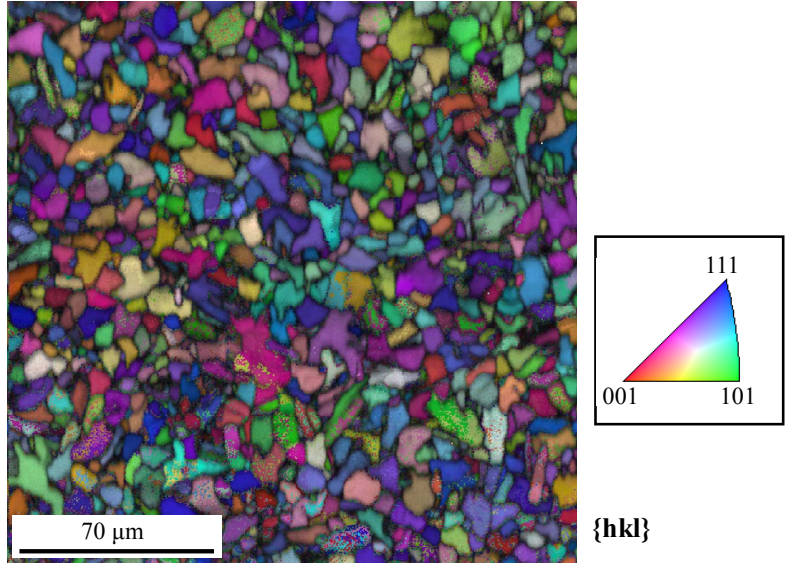

(b)

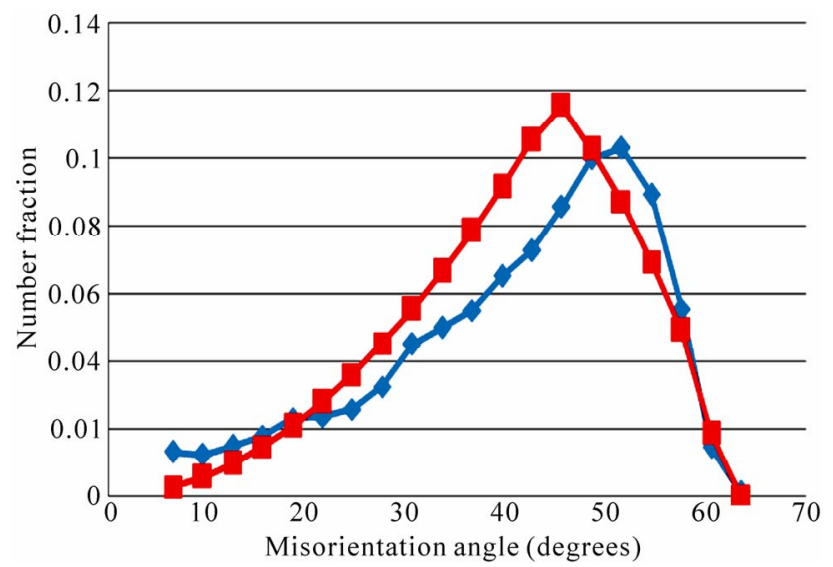

(d)

Figure 2. Microstructures of industrial low carbon steel (0.19 wt. \% C) in base metal by (a) optical and (b) EBSD map-distribution of directions $<$ hkl $>/ /$ z superimposed to the Kikuchi pattern quality factor (c) Histogram of grain size and (d) curves of misorientation distribution (blue: experimental results and red: isotropic distribution).

Widmanstatten ferrite, and some colonies of pearlite. It is known that solid-state phase transformations, such as grain growth, recrystallization, phase transitions, annealing, and tempering, all occur in the HAZ of steel welds. The coarse grained region of the HAZ is adjacent to the weld fusion zone and contains grains larger than those in the base metal. It has been found that there are two phase transformations that occur in the HAZ during cooling. The first is the high temperature transformation of $\delta$-Fe to $\gamma$-Fe. The second transformation is the $\gamma-\mathrm{Fe}$ to $\alpha-\mathrm{Fe}$ transformation [12].

However, Figure 6 shows that the center of weld metal is totally different from the other zones, because it is characterized by pseudo-grains and a microstructural inhomogenity which is a result of the fastest cooling rates. It appears that this zone contains mainly ferrite and some colonies of pearlite. The microstructure that evolved in the weld is heterogeneous due to the temperature gradients and the chemical gradients that evolve during the process [11].
In order to know the main phases in the welded joints (Weld metal + HAZ), XRD diffraction was particularly applied in this region (Figure 7). From three ferrite peaks observed in this spectrum: the bcc (110), bcc (200)

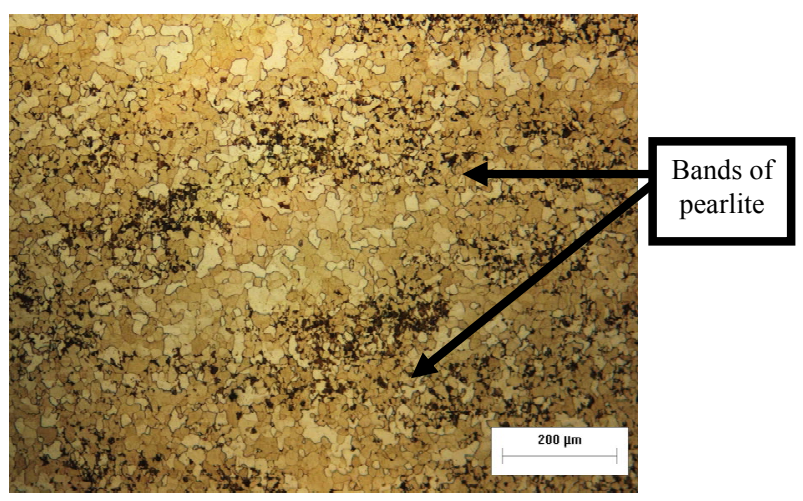

Figure 3. Microstructure of industrial low carbon steel (0.19 wt. \% C) in base metal. 

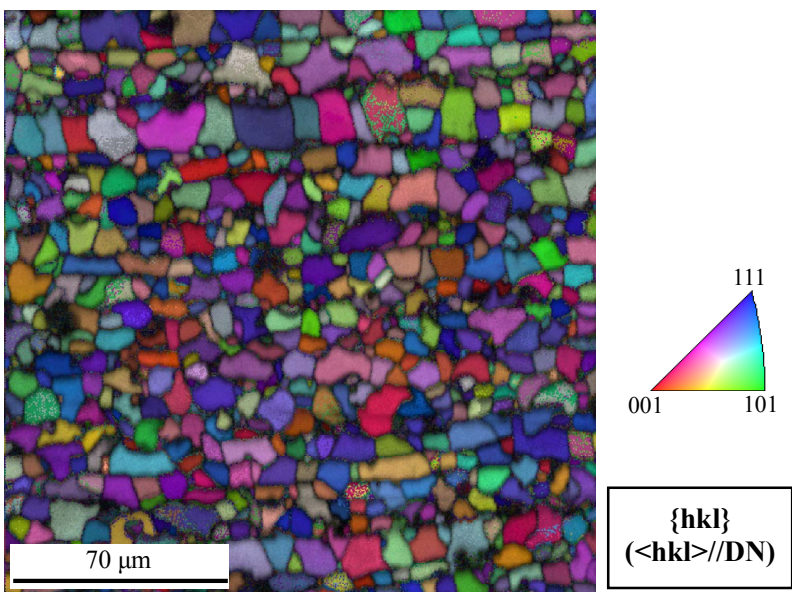

$\{\mathbf{h k l}\}$ $(<\mathbf{h k l}>/ / \mathbf{D N})$

Figure 4. EBSD map (distribution of directions $<$ hkl $>/ / \mathbf{z}$ superimposed to the Kikuchi pattern quality factor) in nearest region to $\mathrm{HAZ}$ after arc welding of an industrial low carbon steel $(0.19$ wt. \% C) (map taken in the base metal but just near the welded metal "near the weld fusion zone").

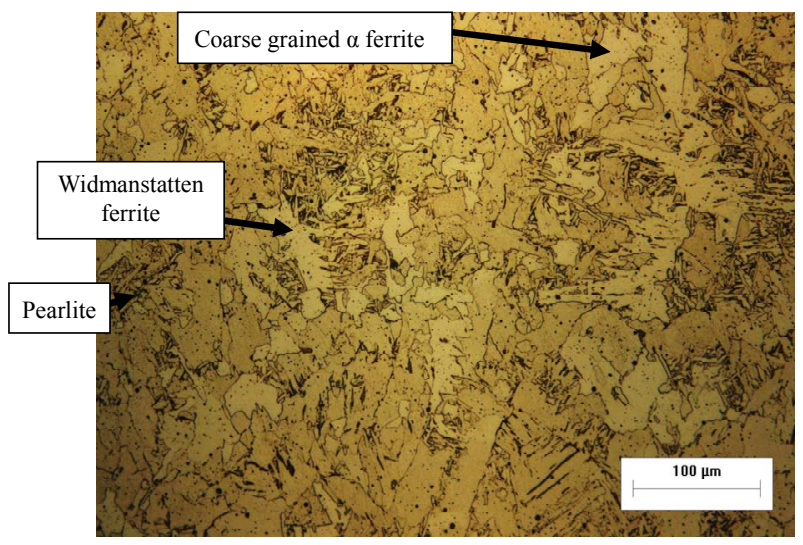

Figure 5. Microstructure of $\mathrm{HAZ}$ after welding of an industrial low carbon steel ( 0.19 wt. \% C).

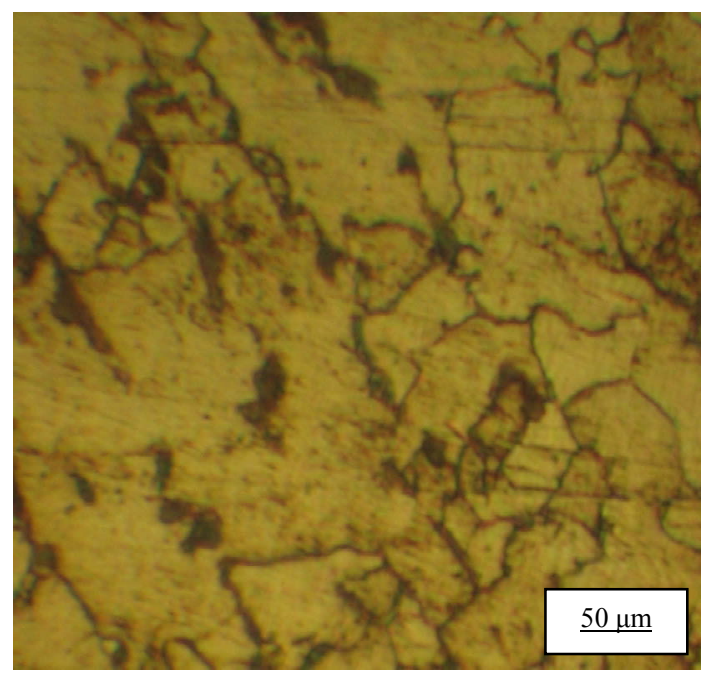

Figure 6. Center of weld metal "in the weld fusion zone".

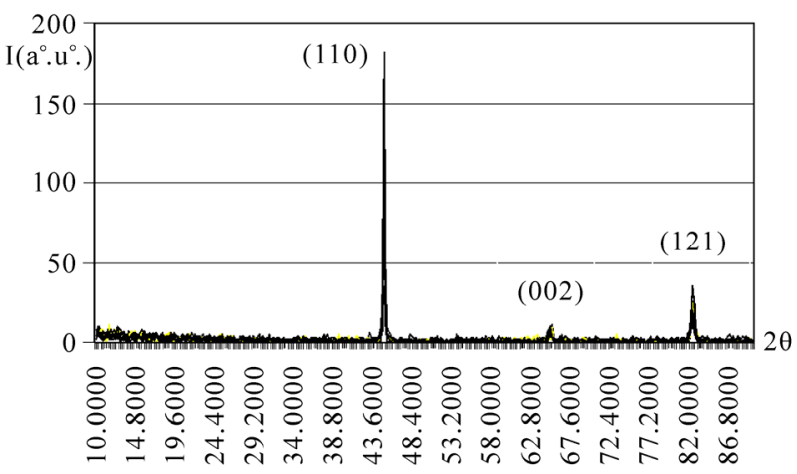

Figure 7. XRD spectrum of welded low carbon steel in all the welded zone (Weld metal + HAZ).

and bec (111), we conclude a presence only of ferrite phase observed by optical microscopy.

On the other hand, by using EBSD observation (Figure 8) a fusion line is determined. We can observe clearly the microstructural difference between weld metal zone and HAZ. This transition zone is characterized by bands of coarse grains, where each band of grain has quite the same orientation (Figure 9). In this coarse-grained zone, it seems that the grains tend to grow along a certain preferred crystallographic directions.

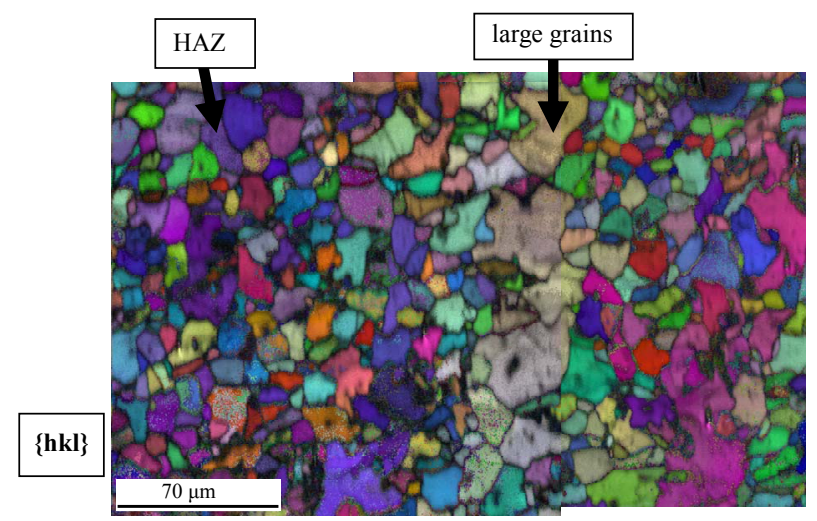

Figure 8. EBSD map (distribution of directions $<\mathrm{hkl}>/ / \mathrm{z}$ superimposed to the Kikuchi pattern quality factor) in transition zone $(4 \mathrm{~mm}$ from the core of weld metal) after arc welding of an industrial low carbon steel (0.19 wt. \% C).

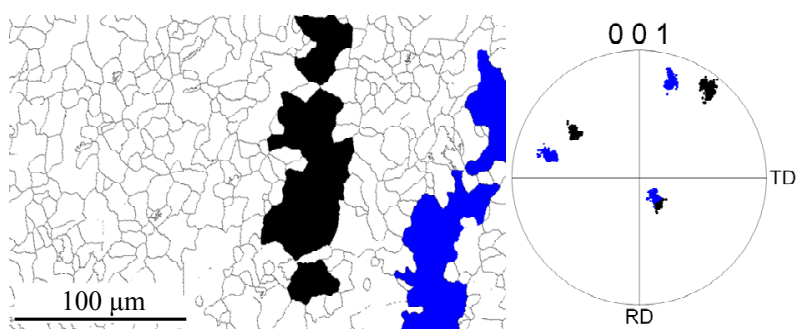

Figure 9. Map of the same EBSD analysis of Figure 8 and corresponding pole figure of the colored grains. 


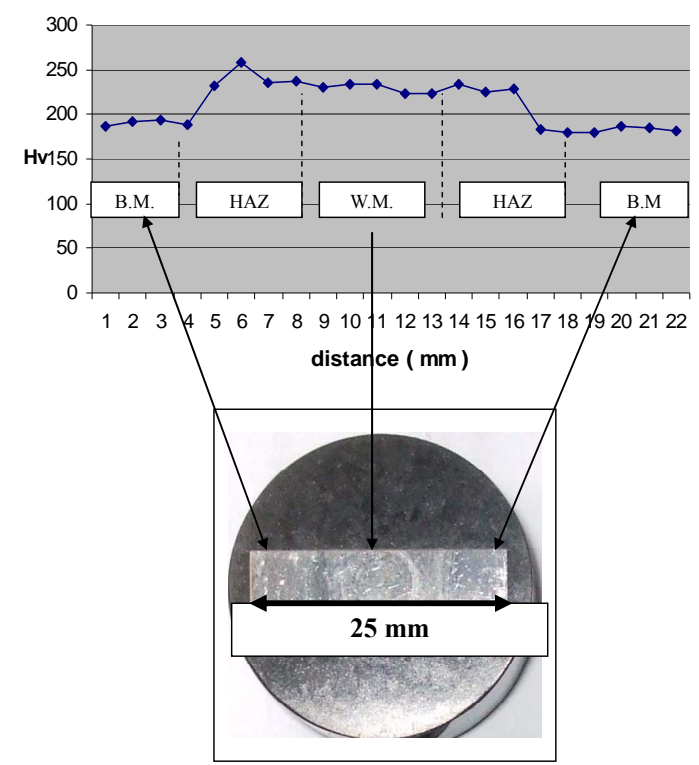

Figure 10. Microhardness measurments on surface S (indicated in Figure 1) from the base metal across the weld metal after welding of an industrial low carbon steel $(0.19$ wt. \% C).

Concerning the effect of welding on different regions of welded steel, it was reported that a hardness testing is the usual approach in delineating the properties of these various zones, but the information obtained is very limited [13]. For other researchers, a simple rapid way to obtain important information is by hardness testing [9]. Concerning the present material, the hardness distribution in different zones is shown in Figure 10. The hardness values of 178-250 HV in Figure $\mathbf{1 0}$ are observed at location within $1 \mathrm{~mm}$ from the base metal, through the HAZ across the weld metal to the other base plate. These hardness results are partially in good agreement with literature. Indeed, Gul et al. [2], have found that maximum hardness values are measured in the area of weld metal (WM). But in the present study, the maximum hardness is both in weld metal and heat-affected zones. The variation in properties across the weld can be attributed to several factors, mainly to residual stresses just after welding. However, other factors can contribute to this hardening like grain size, phase composition and metallic inclusions.

\section{Conclusions}

This work represents a contribution to the study of the effect of shielded metal arc welding on industrial low carbon steel $(0.19$ wt. \% C). The microstructures in different zones are determined from the base metal to the weld metal. The microstructure of the center of weld zone is completely different from the heat-affected zone. The HAZ contains Widmanstatten ferrite, large grains of ferrite and colonies of pearlite. We have observed that bands of coarse grains grow along a certain preferred crystallographic directions. Moreover, we have found that maximum hardness values are situated in the area of weld metal and HAZ which indicates its specificity.

\section{References}

[1] E. Bayaraktar, D. Kaplan, L. Devillers and J. P. Chevalier, "Grain Growth Mechanism during the Welding of Interstitial Free (IF) Steels," Journal of Materials Processing Technology, Vol. 189, No. 1-3, 2007, pp. 114-125.

[2] A. Güral, B. Bostan and A. T. Özdemir, "Heat Treatment in Two Phase Region and its Effect on Welding of a Low Carbon Steel," Materials and Design, Vol.28, No. 3, 2007, pp. 897-903.

[3] Eroglu and M. Aksoy, "Effect of Initial Grain Size on Microstructure and Toughness," Materials Science and Engineering A, Vol. 286, No. 2, 2000, pp. 289-297.

[4] O. Grong and O. M. Akselsen, "HAZ Grain Growth Mechanism in Welding of Low Carbon Microalloyed Steels," Acta Metallurgica, Vol. 34, No. 9, 1986, pp. 1807-1815.

[5] C. Thaulow, A. J. Paauw, A. Gunleiksrud and O. J. Naess, "Heat Affected Zone Toughness of Low Carbon Microalloyed Steel," Metal Construct, Vol. 17, No. 2, 1985, pp. 94-99.

[6] K. Ohaya, J. Kim, K. Yokoyama and M. Nagumo, "Microstructures Relevant to Brittle Fracture Initiation at the Heat-affected Zone of Weldment of Low Carbon Steel," Metallurgical and Materials Transactions A, Vol. 27, No. 9, 1996, pp. 2574-2582.

[7] A. G. Olabi and M. J. S. Hashmi, "The Microstructure and Mechanical Properties of Low Carbon Steel Welded Components after the Application of PWHT," Journal of Material Processing Technology, Vol. 56, No. 1-4, 1996, pp. 88-97.

[8] E. M. Anawa and A. G. Olabi, "Using Taguchi Method to Optimize Welding Pool of Dissimilar Laser-welded Components," Optics \& Laser Technology, Vol. 40, No. 2, 2008, pp. 379-388.

[9] S. Lars-Eric, "Control of Microstructures and Properties in Steel Arc Welds," Library of Congress Cataloging-in-Published Data, British, 1994.

[10] E. Bayaraktar, "IF-steels and Weldability Research Reports Series III," IRSID (ARCELOR) IRSID-MPM 99/20152/1, 2002.

[11] O. Grong, "Metallurgical Modelling of Welding," The Institute of Materials, England, 1994.

[12] J. W. Elmer, J. Wong, T. Ressler and T. A. Palmer, 6th International Conference on Trends in Welding Research, Pine Mountain, 6A, April 2002, pp. 15-19.

[13] G. R. Stewart, A. M. Elwazri, R. Varano, N. Pokutylowicz, S. Yue and J. J. Jonas, "Shear Punch Testing of Welded Pipeline Steel," Materials Science and Engineering A, Vol. 420, No. 1-2, 2006, pp. 115-121. 